\title{
Vibration Signature Analysis for Rotor Broken Bar Diagnosis in Double Cage Induction Motor Drives
}

\author{
Y. Gritli*,***, A. O. Di Tommaso**, R. Miceli**, Member, IEEE, \\ F. Filippetti*, Member, IEEE, C. Rossi, Member, IEEE. \\ * University of Bologna, Italy. \\ Dipartimento di Ingegneria dell'Energia \\ Elettrica e dell'Informazione \\ «Guglielmo Marconi». \\ yasser.gritli@unibo.it, \\ fiorenzo.filippetti@unibo.it, \\ claudio.rossi@unibo.it. \\ ** University of Palermo, Italy. \\ Department of Electrical, Electronic and \\ Telecommunication Engineering, Chemical \\ Technologies, Automatics and Mathematical \\ Models. \\ ditommaso@dieet.unipa.it, \\ rosario.miceli@unipa.it. \\ *** University of Tunis El Manar, Tunisia \\ Department of Electrical Engineering, \\ LARA - National Engineering \\ School of Tunis. \\ yasser.gritli@esti.rnu.tn.
}

\begin{abstract}
The paper investigates the diagnosis of rotor broken bars in field oriented controlled (FOC) double cage induction motor drives, using current and vibration signature analysis techniques. The Impact of the closed loop control system cannot be neglected when the detection of asymmetries in the machine are based on the signature analysis of electrical variables. The proposed diagnosis approach is based on optimized use of wavelet analysis by a pre-processing of phase current or axial/radial vibration signals. Thus, the time evolution of the tracked rotor fault components can be effectively analyzed. This paper shows also the relevance of the fault components computed from axial vibration signal in comparison to those coming from phase current and radial vibration signals. Cyclic fault quantification, issued from the wavelet analysis, has been introduced for accurate rotor fault detection. Experimental results show the validity of the proposed technique, leading to an effective diagnosis procedure for rotor broken bar in double cage induction motor.
\end{abstract}

Keywords- AC Machine; Condition monitoring; double cage rotor; fault diagnostics; induction motor drives; wavelet Transform.

\section{INTRODUCTION}

During the last decades, there has been a considerable amount of research into the creation of new diagnostic procedures with particular attention to renewable energies in general and power conversion related issues. Renewable energies take the centre-stage of international research programs and industrial policies. Power systems design is heavily affected by modern trends in energy saving. In the last few years, improving the power conversion efficiency becomes the key target, often sharply contrasting with system performances [1-2]. A tradeoff between pressing and conflicting requirements on power supply design is brought about. New challenges arise thus pressing both academic and industrial research towards innovative solutions [3-6]. Several applications are heavily affected by efficiency issues. Innovative methods, technologies and solutions have been recently proposed focusing on efficiency related issues [7-8].

Efficient energy consumption is a key factor to Europe's ambitious goals for sustainable development and activities related to air pollution and climate shifting. In order to tackle the increasing electricity demand, a number of solutions for efficient energy consumption, generation of energy from renewable sources, and new power distribution business models for active energy control have been considered and some of them have been even pushed via regulations in national and European level. Since photovoltaic (PV) installed power increases all over the world, solar technology is now strongly present in the electricity market, and it cannot be seen only as a vision of the future. PV generation systems are actually available in different power sizes covering the range from domestic applications to large power generation plants [9-17].

Many different improvements have been proposed and experimented to enhance efficiency not only in energy conversion (PV fields) but also in energy management (power converters). In recent times, multi-level inverters such as $\mathrm{H}$ bridge multi-cell cascaded inverter, Neutral Point Clamped (NPC) and Active Point Clamped (APC) have also been used for a more efficient and effective PV power conversion. Many inverter topologies have been patented, within the market development, to solve some common problems of the PV plants such as leakage currents due to parasitic capacitance of the panel and efficiency losses due to the transfer of reactive energy between the grid filters and the DC bus capacitor. Moreover, some particular topologies have been conceived of for the fault tolerant operation of PV plant [18-27]. In renewable energy sources state of the art an important role is now played from sea electric energies generators [24], between one of the most interesting is the direct generation with a tubular linear generator.

This paper deals with diagnostic procedures for induction machines and drives to overcome the drawbacks of traditional methods. The topic is becoming far more attractive and critical, as the use of electrical machines has gained ground within most areas: the number of operating machines is about 16.1 billion in 2011 , with growth of about $50 \%$ in the last five years [28]. Investigations on different failure modes in induction motors have revealed that $19 \%$ of the overall motor 
faults are related to the rotor part [29]. A detailed analysis of this type of fault can be found in [30]. Double cage rotors are characterized by its large outer (starting) bar resistance and large inner (running) bar leakage inductance. Since double cage motors are used for loaded startups, the outer cage must handle the large starting current for the long acceleration time, with limited path for heat dissipation [31]. Cyclic electromagnetic forces, thermal stress, environmental stress, and mechanical stress associated with the large starting current, make the outer cage more vulnerable to fatigue failure. More specifically, the circulation of inter bar currents reduce the degree of rotor asymmetry, leading to a reduced sensitivity of the related sideband current components. In addition, it was shown that in closed loop drives the control itself affects the behavior of electrical variables and so new diagnostic procedures are necessary for machine monitoring.

More specifically, the MCSA fails for current controlled drives as the control loop masks the oscillation that can occur in the currents under rotor faulty conditions [32-36]. In [35-36], an exhaustive investigation of the impact of the control strategy and even the tuning of the speed regulator was considered as potential criteria for the selection of the appropriate motor fault diagnosis technique. Different techniques are used to provide accurate non-invasive on-line condition monitoring of induction motors. These methods are based on a different reference quantity or on advanced signal processing techniques, or on combination of the above. Instead of stator current, mechanical or electrical quantities were used as reference signal to detect the presence of rotor faults. Modulated signals were investigated in steady-state condition and then under-time varying conditions respectively in [32] and [33] to overcome the compensating effect of the control system on current harmonics to diagnose rotor faults. In [34], tests carried out on an induction machine controlled by a fieldoriented control prove that the spectrum of the field current is a good diagnostic index, since it is strongly dependent on the asymmetry level and quite independent of the control parameters.

A new technique has been presented in [37], where the electromagnetic torque_magnitude is computed in different ways as a function of rotor position, to detect the presence of rotor faults. [38-39] are referred to detection of broken bars by external magnetic field analysis. On the other hand, vibration signature analysis was investigated in [40-44], showing the effectiveness of this technique in diagnosing rotor broken bars in induction motors. The situation is more critical, when the frequency components characteristics of the rotor fault are very close to the fundamental one, and specifically under low load operating conditions [40-41]. In order to discern cases in which the presence of inter bars currents decrease the sensitivity of the MCSA, axial and radial vibrations analysis were investigated in [42], and more recently for double cage motor in [43]. On the other hand, the rotor current mainly flows in the symmetric inner cage under steady state operating condition, and fault signature is insensitive to outer cage damage. A combined use of current and vibration analysis was developed, by correlating the signal spectra to enhance broken bars detection ability under loaded and unloaded operating conditions of the motor in [44].

It should be noted that for the above listed contributions, referred to the detection of broken bars based on vibration signature analysis, the applications are considered for lineconnected motors.

On the other hand, the fault components, issued from the above listed signals, whose amplitudes must be monitored for diagnostic purposes, were mainly investigated in frequency domain using the classical Fourier Analysis (FA). The techniques based on FA give satisfactory discrimination between healthy and faulty conditions, but don't provide time domain information necessary for on-line fault detection. A solution was proposed in [43] to extract accurately the contribution of the fault components, issued from vibration signals and related to rotor broken bar in double cage induction motor, under steady-state condition, based on improved performance of wavelet analysis.

In this paper, a new diagnostic index that allows the extraction of rotor fault components issued from axial vibration signals, is defined to improve the fault quantification procedure. A simple sliding frequency procedure in the time domain that processes the vibration signals is proposed. After the Frequency Sliding (FS) process, the contribution of the fault components of interest are confined in a single frequency band and extracted thereby via Wavelet Transform Analysis.

\section{Rotor FAULt COMPONENT PROPAGATION}

Like any other rotating electrical machine, the double cage induction motor is subjected to electromagnetic and mechanical forces symmetrically repartitioned. In healthy conditions only the fundamental frequency $f$ exists in stator currents $(f$ : supply frequency). If the rotor part is damaged, the rotor symmetry of the machine is lost producing a reverse rotating magnetic field related to an inverse sequence component at frequency $-s f$. This inverse sequence is reflected on the stator side, producing the frequency $(1-2 s) f$. These frequency components generate electromagnetic and mechanical interactions between stator and rotor parts. Consequently torque and speed ripple effects are generated at frequency $2 s f$, which modulate the rotating magnetic flux [30]. This modulation produces two current components, i.e., an additional left-side component at $(1-2 s) f$ and a right side component at $(1+2 s) f$. Following this interaction process, the frequency content of the stator currents show series of fault components at the following frequencies $((1 \pm 2 k s) f)_{k=1,2,3, \ldots}$. More specifically, for large or double squirrel-cage motors, as long as the contact impedance between the rotor bars and iron core is small or the copper bars are directly inserted into the laminated iron slots, the broken bar is no longer a physical condition ensuring an open circuit and inter bars or cross-path currents can flow. As a consequence, these inter bar transverse currents interact with the radial stator flux density, generating axial forces. These facts lead mainly to the presence of a first chain of fault frequency components at $\left(f_{\text {mec }} \pm 2 k s f\right)_{k=1,2,3, \ldots}$, and a second one at $((6-2 k s) f)_{\mathrm{k}=1,2,3, \ldots}$, in radial and axial vibration directions $\left(f_{\text {mec }}\right.$ denotes the mechanical speed of the motor) [41]. In the next sections, the focus will be on tracking the most 
relevant fault components of the harmonic chains $((1 \pm 2 k s) f)_{k=1,2,3, \ldots)}$. and $\left(f_{\text {mec }} \pm 2 k s f\right)_{k=1,2,3, \ldots}$ in frequency domain, and in time-frequency domain thereby. As demonstrated in [43], the most relevant fault components for the above chains of harmonics are $(1-2 s) f$ and $\left(f_{m e c}-2 s f\right)$ corresponding to Motor current Signature Analysis (MCSA) and Motor Vibration Signature Analysis (MVSA) respectively. Hence, the investigations below will be focused exclusively on these two rotor fault components $(1-2 s) f$ and $\left(f_{m e c}-2 s f\right)$.

\section{EXPERIMENTAL SETUP}

Indirect rotor field oriented control is one of the most widely used control strategy for induction motor drives in industrial applications. As shown in Fig. 1. the double cage induction motor control system is based on two cascaded loops. The outer loop is dedicated to the speed control. Whereas the inner one is related to the control of the direct and quadrature stator current components. The blocks containing $D$ and $D-1$ represent respectively the Clarke's and the inverse Clarke's transformations from a three phase to a two phase d-q system. classical PI regulator is used to generate the reference value of the torque, which produce the current component $\mathrm{i}_{\mathrm{qs}} *$. Two high bandwidth current PI regulators are used for generating the direct and quadrature quantities $\mathrm{v}_{\mathrm{sd}}{ }^{*}$ and $\mathrm{v}_{\mathrm{sq}}{ }^{*}$ voltage respectively.

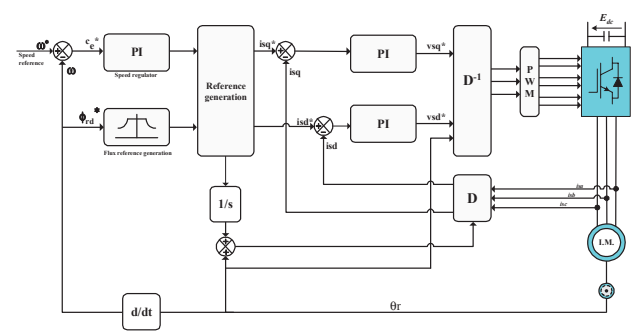

Fig. 1. Block diagram of the control scheme for a typical indirect field-oriented control induction motor drive.

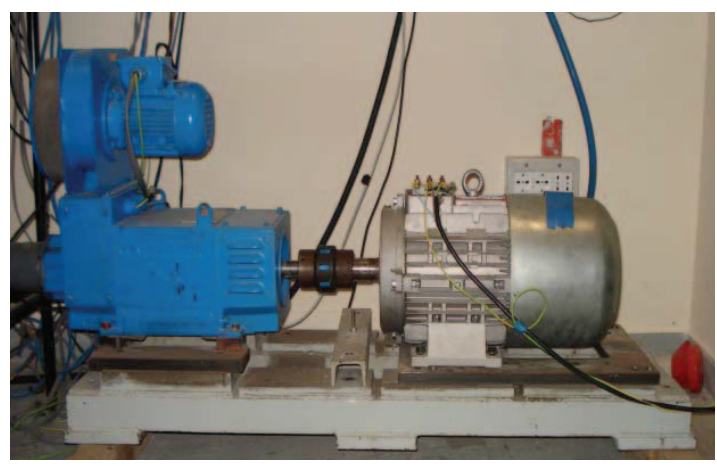

Fig. 2. Experimental test-bed.
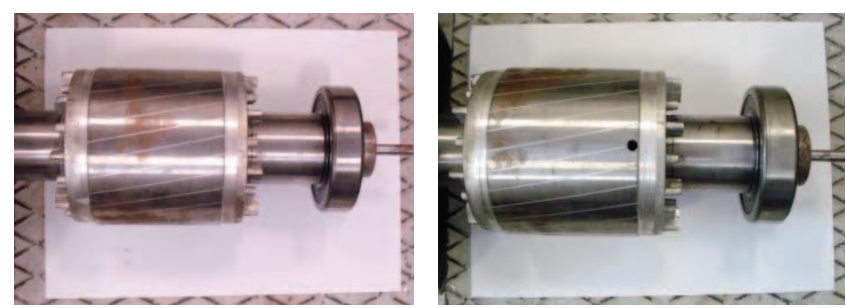

Fig. 3. Photos of the healthy (left), and the drilled rotor bar (right).
On the other hand, the rotor position angle $\theta r$ is determined thanks to the incremental encoder present in the control system. In order to evaluate the sensitivity of the rotor fault components issued from MCSA and MVSA based on the proposed diagnosis technique, a complete set of experimental tests have been carried out. Fig. 2 shows details of the experimental test-bed. For this purpose, the frequency analysis has been applied to the stator current, radial and axial vibration signals, considering the healthy and the faulty double cage induction motors. For this purpose, two double cage induction motors are available; one healthy, and the second with a drilled broken bar (the bar was completely disconnected from the common end-ring). Photos of the used healthy and faulty double cage rotors are shown in Fig. 3. The characteristics of the double cage induction motors used for experiments are presented in Table I. A PWM-VSI converter is used to control the motor. A dSPACE system based on the DS1103 control board has been used to implement the indirect rotor field oriented control shown in Fig. 1. Two piezoelectric accelerometers Brüel \& Kjær model 4507 B 005, were mounted for measuring axial and radial vibrations of the core motors. A NEXUS 2693 model as signal conditioner is used for vibration signals. The control board is also used for data acquisition and data processing. The experimental tests have been performed by operating the machine under load-varying conditions according to the slip profile presented in Fig. 4. The corresponding instantaneous values of stator frequency and speed are shown in Fig. 5

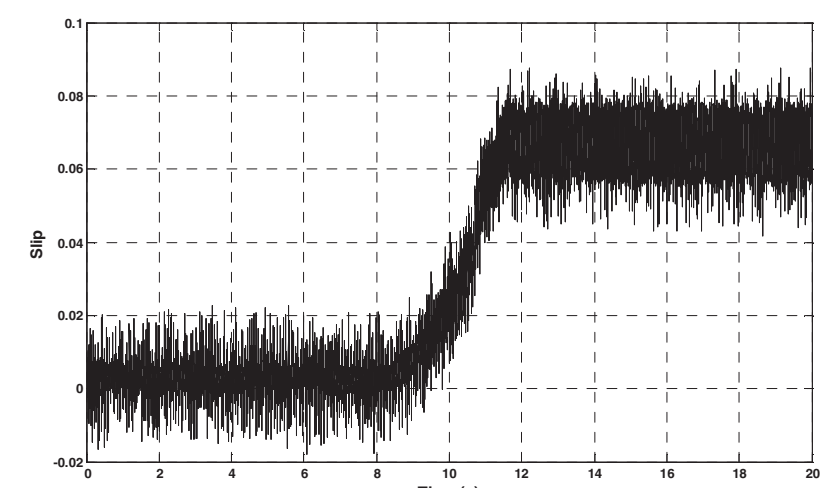

Fig. 4. Experimental results for the used double cage induction motor in faulty conditions, under load-varying conditions. Instantaneous values of slip.

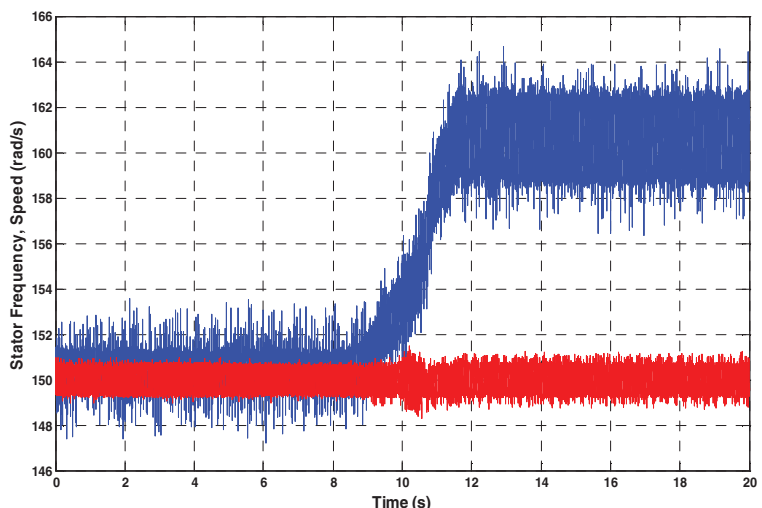

Fig. 5. Experimental results for the used double cage induction motor in faulty conditions, under load-varying conditions. Stator frequency (blue), and speed 
TABLE I. INDUCTION MOTOR PARAMETERS

\begin{tabular}{|c|r|r|}
\hline Data & \multicolumn{2}{|c|}{ Value } \\
\hline Rated Power & $\mathrm{kW}$ & 5.5 \\
\hline Rated stator voltage & $\mathrm{V}$ & 400 \\
\hline Rated current & $\mathrm{A}$ & 13 \\
\hline Rated frequency & $\mathrm{Hz}$ & 50 \\
\hline Rated speed & $\mathrm{rpm}$ & 2870 \\
\hline Rotor diameter & $\mathrm{mm}$ & 110 \\
\hline Axial length of the rotor & $\mathrm{mm}$ & 90 \\
\hline Air gap length & $\mathrm{mm}$ & 0.5 \\
\hline
\end{tabular}

\section{MCSA AND MVSA FOR ROTOR BROKEN BAR DETECTION BASED FREQUENCY DOMAIN}

In this section, the detectability of rotor broken bar using MCSA and MVSA under load-varying operating conditions is presented and discussed. Fig. 6. shows the spectra, issued from experimental results under load-varying conditions, for healthy and one rotor broken bar. The spectrum of the healthy machine is considered as reference in comparison to the faulty case. The magnitudes are normalized to the value of the fundamental harmonic component. Due to the damping effect of the machine-load inertia on higher order fault harmonics, the focus is exclusively on tracking the most relevant fault frequency (1$2 s) f$ in the stator currents. Observing Fig. 6, it can be seen clearly that no signature analysis is possible for such cases, due to the large spreading of frequency. Hence the contribution of the $(1-2 s) f$ related to the rotor broken bar spread in a wide frequency range. In addition, practically, there is no significant contribution of the fault component of interest $(1-2 s) f$ and this is mainly due to the control compensating effect of the fault impact on currents. For the same load-varying conditions, radial and axial vibrations were recorded and analyzed. Radial vibration signal spectra close to the mechanical frequency $f_{m e c}$ are depicted in Fig. 7, during the considered load-transient conditions. As it can be seen, under one rotor broken bar, that the contribution of the left side component $\left(f_{m e c}-2 s f\right)$ can't be detected in a significant way in comparison to the healthy case. Hence, no signature analysis is possible for such cases, due to the large spreading of frequency.As a preliminary conclusion, it can be seen that the fault signature issued from motor current analysis (Fig. 6), and radial vibration analysis (Fig. 7), show practically the same low level of sensitivity. Moreover the fault components amplitudes have a very low level, even if there is a relevant change passing from healthy to faulty condition. Obviously this behavior complicate the fault detection, and makes also this fault components not suitable for an efficient fault analysis. Let us now focus on the axial vibration signature analysis. Axial vibration signal spectra around the mechanical frequency $f_{m e c}$ are depicted in Fig. 8 for the considered loadvarying conditions, and under healthy (black) and one rotor broken bar (red) respectively. As it can be observed, under one rotor broken bar, the left side component $\left(f_{\text {mec }}-2 s f\right)$ increases in a significant way in comparison to the healthy condition. But the main problem is the spreading effect observed for the fault component $\left(f_{\text {mec }}-2 s f\right)$ during due to the slip variations that can be observed in Fig. 4. Comparing Fig. 6, Fig. 7 and Fig. 9, it can be seen that the signature issued from axial vibration analysis is more relevant than the one issued from MCSA and MRSVA. More specifically, the fault component $\left(f_{m e c}-2 s f\right)$ issued from axial vibration analysis is the most relevant component at this level of investigation.

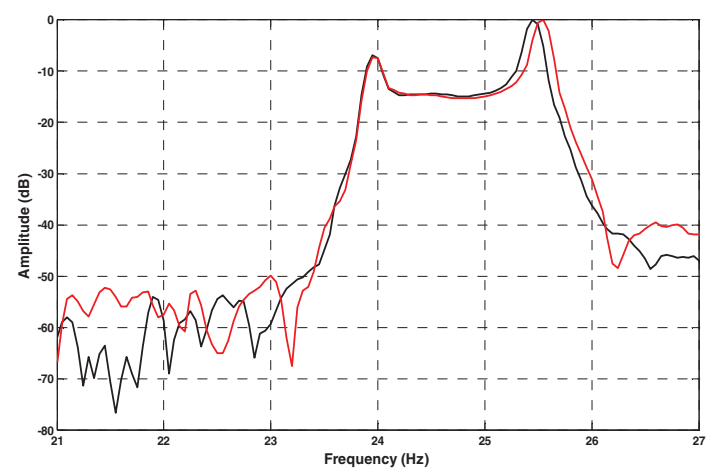

Fig. 6. Experimental results: Stator phase current spectra, under load-varying conditions, for healthy (black) and rotor broken bar (red).

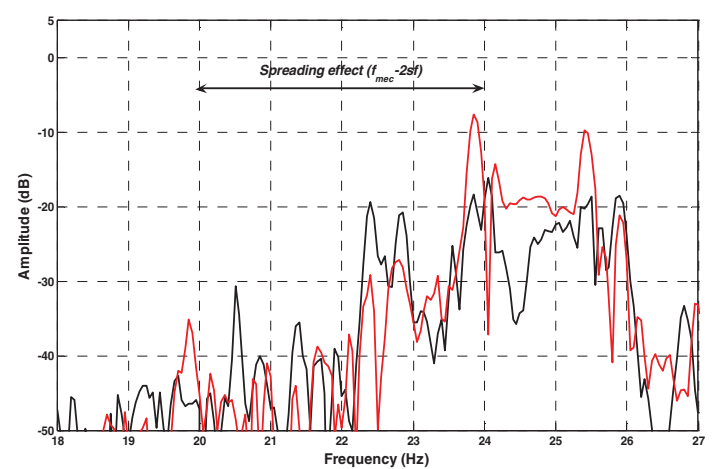

Fig. 7. Experimental results: Rxial vibration spectra, under load-varying conditions, for healthy (black) and rotor broken bar (red).

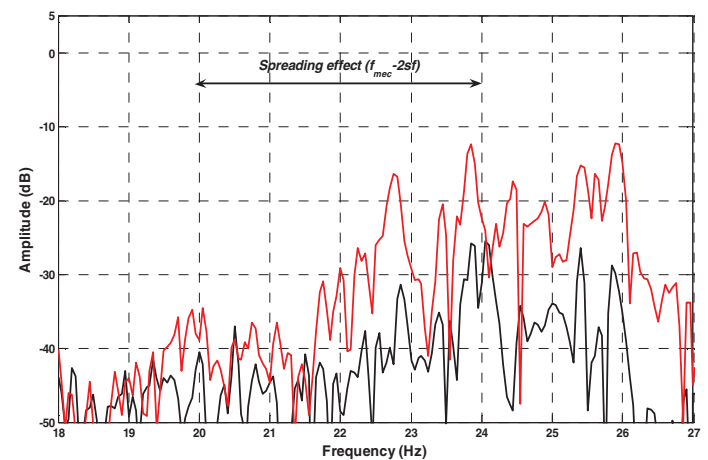

Fig. 8. Experimental results: Axial vibration spectra, under load-varying conditions, for healthy (black) and rotor broken bar (red).

Finally, due to the relevance of the signature tracked by axial vibration signature analysis (MAVSA), in comparison to the results issued from MCSA and MRSVA, the presence of inter bar currents is evidenced. Effectively, the presence of inter bar currents compensate the rotor unbalance of the machine, resulting in a reduced sensitivity of the fault components issued from both motor current and radial vibration analysis. In addition, the control system compensate the effect of rotor fault and also reduce the contribution of the above signatures in currents and radial vibration signals. 
Then, a more appropriate technique is needed for providing a reliable diagnosis procedure. In the next section, a simple and effective new technique is proposed, providing reliable information in Time-Frequency domain about rotor broken bar detectability in double squirrel cage induction motor

\section{THE PROPOSED APPROACH BASED ON WAVELET ANALYSIS}

Effectively, the above listed chains characteristics of rotor fault conditions, were extensively investigated in frequency domain for diagnosis purposes. The main focus was exclusively on the frequency content of signals without time domain information, which is mandatory for an on-line fault detection system. On the other hand wavelet transform (WT) provides greater resolution in time domain for high frequency components of a signal and greater resolution in frequency domain for low frequency components.

Wavelet analysis is signal decomposition, using successive combination of approximation and detail signals. The procedure is repeated until the original signal is decomposed to a pre-defined J level decomposition. With the well known dyadic down sampling procedure, frequency bands of each level of decomposition are related to the sampling frequency.

TABLE II.

FREQUENCY BAND OF EACH LEVEL

\begin{tabular}{|c|c|c|c|}
\hline $\begin{array}{r}\text { Approximations } \\
\left\|a_{j}\right\|\end{array}$ & $\begin{array}{l}\text { Frequency } \\
\text { Bands }(\mathrm{Hz})\end{array}$ & $\begin{array}{r}\text { Details } \\
\left\|d_{j}\right\|\end{array}$ & $\begin{array}{l}\text { Frequency } \\
\text { bands }(\mathrm{Hz})\end{array}$ \\
\hline$a_{8}$ & $:[0-6.25]$ & $d_{8}$ & $:[6.25-12.5]$ \\
\hline$a_{7}$ & $:[0-12.5]$ & $d_{7}$ & $:[12.5-25]$ \\
\hline$a_{6}$ & $:[0-25]$ & $d_{6}$ & $:[25-50]$ \\
\hline$a_{5}$ & $:[0-50]$ & $d_{5}$ & $:[50-100]$ \\
\hline$a_{4}$ & $:[0-100]$ & $d_{4}$ & $:[100-200]$ \\
\hline$a_{3}$ & $:[0-200]$ & $d_{3}$ & $:[200-400]$ \\
\hline$a_{2}$ & $:[0-400]$ & $d_{2}$ & $:[400-800]$ \\
\hline$a_{1}$ & $:[0-800]$ & $d_{1}$ & $:[800-1600]$ \\
\hline
\end{tabular}

Hence, these bands can't be changed unless a new acquisition with different sampling frequency is made. This fact complicates any fault detection procedure based on Wavelet Transform, particularly in time-varying condition.

In this paper, an efficient solution to overcome this limitation is proposed. With a sampling frequency $f_{s}=3.2 \mathrm{kHz}$, a seven level decomposition $(J=8)$ was chosen in order to cover the frequency bands in which we can track the contribution of the fault component $f_{m e c}-2 s f$. The frequency band repartition corresponding to the above decompositions are presented in Table. II. In healthy conditions, only the fundamental component $f_{m e c}$ exists in vibration signals. If the rotor part is damaged, the first fault frequency component that occurs in the axial vibration direction is $f_{m e c}-2 s f$ where $\mathrm{s}$ is the slip. In order to sense the contribution of this fault component in timefrequency domain, an optimal use of wavelet analysis is here proposed to detect rotor bar breakage with high precision.

A simple processing of the axial vibration signal allows shifting the fault component $f_{m e c}-2 s f$ to a prefixed frequency band. In such a way, all the information related to the fault is isolated and confined in a single frequency band. More in detail, a frequency sliding with $f_{s l}$ is applied at each time slice to the axial vibration signal as in (1), so that the harmonic component of interest is moved to a frequency band, in which the fault component will be tracked.

$$
V_{s l}(t)=\operatorname{Re}\left[v_{a x}(t) e^{-j 2 \pi f} s l^{t}\right]
$$

Then the real part of the shifted signal is analyzed by means of DWT. Hence, with respect to the frequency bands reported in Table II, the frequency band of interest, for tracking the $f_{m e c^{-}}$ $2 s f$ frequency contribution is the corresponding to the $8^{\text {th }}$ approximation signal.

\section{ROTOR BROKEN BAR DETECTION BASED TIME- FREQUENCY DOMAIN}

As explained in the previous section, the fault component $f_{\text {mec }}-2 s f$, will be tracked in the frequency band [0:6.25], after appropriate frequency sliding applied to axial vibration signals. All signals reported have been recorded during 20 seconds.

The wavelet decompositions of the axial vibration signals in healthy condition, is used as references in comparison to the faulty case.

During the considered load-varying conditions, the investigated axial vibration signals, used for the frequency analysis presented in Fig. 8 under healthy and one drilled broken bar are depicted in Fig. 9 and Fig. 10 respectively. These results were obtained after a frequency sliding of $25.125 \mathrm{~Hz}$ applied to the axial vibration signals $v_{a x}$ under healthy and one rotor broken bar condition according to (1).

In healthy condition, the approximation signal of interest $\left(a_{8}\right)$, depicted in Fig. 9, shows very low variations. This indicates the absence of the rotor fault component $f_{\text {mec }}-2 s f$, leading to diagnose the healthy condition of the motor under load-varying conditions. Under faulty condition, the contribution of the rotor fault component $f_{m e c}-2 s f$, observed on the $8^{\text {th }}$ approximation signal (Fig. 10), is very relevant in comparison to the healthy case (Fig. 9).

More in detail, the oscillations observed in the signal $a_{8}$, follow a characteristic pattern that fits the evolution in frequency of the considered rotor fault component $f_{m e c}-2 s f$. Effectively, the variations observed in the approximation signal $a_{8}$ is evident in faulty case in comparison to the healthy one, leading to a clear discrimination between healthy and faulty conditions, through the evolution of the wavelet signal $a_{8}$.

Finally, the obtained results from the above experimental tests show the reliability and the significant relevance of the signatures issued from MAVSA, which behaves as a good diagnostic index for rotor broken bars in double cage induction motors operating under load-varying conditions. The developed approach has provided a satisfactory level of accuracy, indicating a promising performances for the 
detection of incipient rotor broken bars (cracked or broken bars in the outer rotor cage, ...).

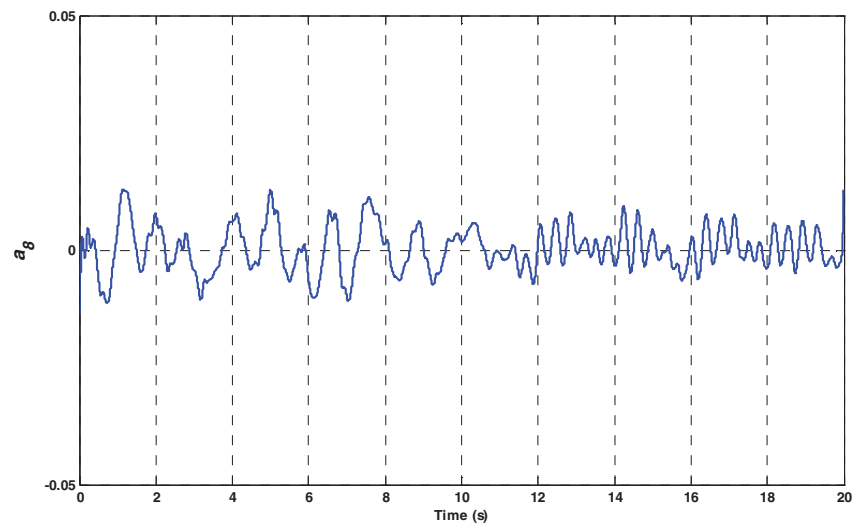

Fig. 9. Wavelet decomposition of $V_{s l}(t)$, issued from axial vibration signal, in healthy conditions, and under load-varying conditions.

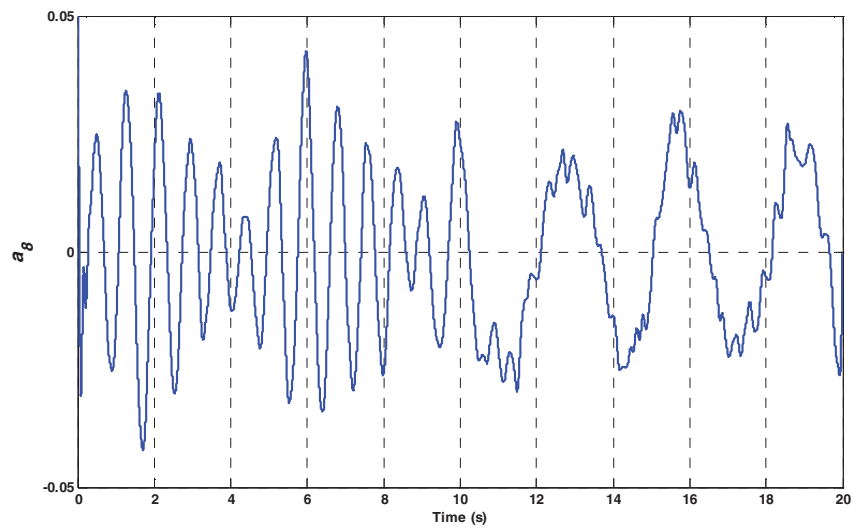

Fig. 10. Wavelet decomposition of $V_{s l}(t)$, issued from axial vibration signal, for rotor broken bar conditions, and under load-varying conditions.

\section{CONCLUSIONS}

The applicability of the classical motor current signature analysis technique, based on FA may fail due to the presence of inter bar currents, and the impact of the IRFOC strategy, which reduce the amplitude of the tracked fault component in frequency domain. Vibration analysis may not only detect the existence of inter bar currents under broken bar failure, but also enhance the detectability of this type of fault by considering advanced use of signal processing techniques. For small induction motors, the MCSA diagnostic procedure is still effective. But, with high power or double cage motor, like the tested one, the use of vibration analysis is mandatory in order to avoid erroneous diagnosis.

The signature issued from axial vibration analysis is relevant, for the investigated rotor fault component $f_{m e c}-2 s f$. Under low load operating conditions, the most relevant fault components become very close to the fundamental ones, which complicate the diagnosis procedure for this type of motors. Adding, the spreading effect of the fault component of interest, under load-varying operating conditions, Time-Frequency domain analysis become mandatory for reliable diagnosis process.
Quantifying the contribution of the considered rotor fault component in Time-Frequency domain is our main challenge in the future to guaranty a reliable rotor broken bar fault signature in a double cage induction motor drives.

\section{REFERENCES}

[1] G.M. Di Blasi, V. Boscaino, P. Livreri, F. Marino, M. Minieri, "A Novel Linear-Non-Linear Digital Control for DC/DC Converter with Fast Transient Response", Proceedings of the IEEE Applied Power Electronics Conference, APEC'06, vol.1, pp.705-711, DOI:10.1109/APEC.2006.1620616.

[2] V. Boscaino, P. Livreri, F. Marino, and M. Minieri , "Linear-non-linear Digital Control for DC-DC Converters with Fast Transient Response", Int. Journ. of Power and Energy Sys., 2009, vol. 29, pp.38-47. DOI: 10.2316/Journal.203.2009.1.203-4021.

[3] V. Boscaino, G. Capponi, G.M. Di Blasi, P. Livreri, and F. Marino, "Modeling and simulation of a digital design approach for power supply systems", Proceedings of the IEEE Workshops on Computers in Power Electronics, COMPEL 2006, USA 2006, pp.246-249. DOI: 10.1109/COMPEL.2006.305638.

[4] V. Boscaino, G. M. Di Blasi, P.Livreri, F. Marino, M. Minieri “A novel digital control technique for $\mathrm{DC} / \mathrm{DC}$ converters to improve steady-state performances", Annual International Telecommunications Energy Conference, INTELEC 2006, Sept. 2006, pp. 1-4.

[5] V. Boscaino, P. Livreri, F. Marino, and M. Minieri, "Current-Sensing Technique for Current-Mode Controlled Voltage Regulator Modules". Microelectronics Journal, Elsevier, vol.39, no.12, pp.1852-1859, 2008 , DOI: 10.1016/j.mejo.2008.05.015, Dec. 2008.

[6] V. Boscaino and G. Capponi, "A High-Efficiency, Low-Cost Solution for On-Board Power Converters", Advances in Power Electronics, Hyndawi, vol. 2012, pp. 1-12. doi:10.1155/2012/259756, Sept. 2012.

[7] F. Pellitteri, V. Boscaino, R. La Rosa, and G. Capponi, "Improving the efficiency of a Standard Compliant Wireless Battery Charger", in IEEE International Universities Power Engineering Conference, UPEC 2012, UK, 2012, DOI: 10.1109/UPEC.2012.6398572, pp. 1-5.

[8] V. Boscaino, F. Pellitteri, G. Capponi, and R. La Rosa, "A Wireless battery charger Architecture for Consumer Electronics", in IEEE International Conference on Consumer Electronics, ICCE 2012, Germany, 2012, pp.84-88. Doi: 10.1109/ICCE-Berlin.2012.6336483.

[9] Di Dio V., La Cascia D., Miceli R. Rando C., "A mathematical model to determine the electrical energy production in photovoltaic fields under mismatch effect". 2009 International Conference on Clean Electrical Power, ICCEP Capri, 9-11 June 2009. Pages 46-51. ISBN: 978142442544-0. DOI: 10.1109/ICCEP.2009.5212083.

[10] V. Boscaino, G. Capponi, P.Livreri, and F. Marino, "Fuel Cell Modelling for Power Supply Systems Design". Proceedings of the IEEE International Workshop on Control and Modeling for Power Electronics, COMPEL'08, Zurich, $2008 . \quad$ pp.1-5. DOI:10.1109/COMPEL.2008.4634671.

[11] V. Boscaino, G. Capponi, and F. Marino, "FPGA implementation of a fuel cell emulator", Proceedings of the 20th IEEE International Symposium on Power Electronics, Electrical Drives, Automation and Motion, SPEEDAM' 10, Italy, 2010, pp. 1297-1301. DOI: 10.1109/SPEEDAM.2010.5542090.

[12] V. Boscaino, G. Capponi, P. Livreri, and F. Marino, "Measurementbased Load Modelling for Power Supply Systems Design" Proceedings of the IEEE Workshops on Computers in Power Electronics, COMPEL 2008, Zurich, 2008,pp. 1-4. Doi:10.1109/COMPEL.2008.4634672.

[13] V. Di Dio, D. La Cascia, R. Liga, and R. Miceli, "Integrated mathematical model of proton exchange membrane fuel cell stack (PEMFC) with automotive synchronous electrical power drive," in Electrical Machines, 2008. ICEM 2008. 18th International Conference on, 2008, pp. 1-6. DOI: 10.1109/ICELMACH.2008.4800045.

[14] D. Bonanno, F. Genduso, R. Miceli, and C. Rando, "Main Fuel Cells mathematical models: Comparison and analysis in terms of free parameters," in Electrical Machines (ICEM), 2010 XIX International 
$\begin{array}{lrrrr}\text { Conference on, 2010, } & \text { pp. } & 1-6 . & \text { DOI: }\end{array}$ 10.1109/ICELMACH.2010.5608225

[15] V. Boscaino, G. Capponi, and F. Marino, "Experimental test on a fuel cell-supercapacitor hybrid power supply for a digital still camera" Proceedings of the IEEE International Universities Power Engineering Conference, UPEC'09, Scotland, 2009, pp.1-5.

[16] V. Boscaino, G. Capponi, P. Livreri, F. Marino "A fuel cell-based hybrid power supply for portable electronics devices", IEEE International Conference on Electronics, Circuits \& Systems, ICECS 2008, 31 Agosto - 3 Settembre 2008, pp. 69-72.

[17] V. Boscaino, R. Collura, G. Capponi, and F. Marino, "A fuel cell battery hybrid power supply for portable applications". Proceedings of the 20th IEEE International Symposium on Power Electronics, Electrical Drives, Automation and Motion, in Int. Symp. Power Electron. Elect. Drives Automation and Motion, SPEEDAM'10, Italy,2010,pp.580-585, DOI: 10.1109/SPEEDAM.2010.5542091.

[18] Di Tommaso, A.O., Genduso, F. , Miceli, R., "Analytical investigation and control system set-up of medium scale PV plants for power flow management”, Energies, Vol. 5, no. 11, Nov. 2012, Pages 4399-4416. ISSN: 19961073. DOI: 10.3390/en5114399.

[19] Di Tommaso, A.O., Genduso, F., Miceli, R. "A geometrical simple approach for power silicon devices fault detection and fault-tolerant operation of a voltage source inverter". Proceedings - 2012 20th International Conference on Electrical Machines, ICEM 2012. Pages 1526-1532, Marseille, 2 - 5 September 2012.ISBN: 978-146730142-8. DOI: 10.1109/ICEIMach.2012.6350081.

[20] Cecati C., Genduso F., Miceli, R., Ricco Galluzzo G., "A suitable control technique for fault-tolerant converters in distributed Generation".Proceedings - ISIE 2011: 2011 IEEE International Symposium on Industrial Electronics 2011, Pages 107-112, Gdansk, 27 30 June 2011. ISBN: 978-142449312-8. DOI: 10.1109/ISIE.2011.5984141.

[21] Di Tommaso A O, Genduso F, Miceli R, Ricco Galluzzo G. "Computer Aided Optimization Via Simulation Tools of Energy Generation Systems With Universal Small Wind Turbines". In: 3rd IEEE International Symposium on Power Electronics for Distributed Generation Systems (PEDG) 2012. Aalborg, Denmark, June 25-28 2012, p. 570-577, Piscataway (NJ):IEEE, ISBN: 978-1-4673-2022-1, doi: 10.1109/PEDG.2012.6254059

[22] Di Tommaso AO, Favuzza S, Genduso F, Miceli R, Ricco Galluzzo G. "Development of Diagnostic Systems for the Fault Tolerant Operation of Micro-Grids". In: SPEEDAM 2010 - International Symposium onPower Electronics, Electrical Drives,Automation and Motion. Pisa, Italy, June 14th-16th, 2010, p. 1645-1650, Piscataway (NJ):IEEE, ISBN: 978-14244-7919-1, doi: 10.1109/SPEEDAM.2010.5542262

[23] Genduso F., Miceli, R., "A general mathematical model for nonredundant fault-tolerant inverters"2011 IEEE International Electric Machines and Drives Conference, IEMDC 2011.Pages 705-710, Niagara Falls, 15 - 18 May 2011. DOI: 10.1109/IEMDC.2011.5994897.

[24] Di Dio V., Miceli R., Trapanese M., "The use of sea waves for generation of electrical energy: A linear tubular asynchronous electrical generator", Oceans 2007 MTS/IEEE conference;Vancouver, BC, 29 Sept.- 4 Oct. 2007.ISSN: $01977385 . \quad$ DOI: 10.1109/OCEANS.2007.4449423.

[25] Gritli Y, Di Tommaso A O, Filippetti F, Miceli R, Rossi C, Chatti C. "Investigation of Motor Current Signature and Vibration Analysis for Diagnosing Rotor Broken Bars in Double Cage Induction Motors" . In: Proc. of the 2012 International Symposium on Power Electronics,Electrical Drives, Automation and Motion.(SPEEDAM 2012) Sorrento (Italy), 20-22 Giugno 2012, p. 1360-1365, Piscataway (NJ):IEEE, ISBN: 978-1-4673-1301-8. 10.1109/SPEEDAM.2012.6264465

[26] Di Tommaso A O, Miceli R, Ricco Galluzzo G. "Monitoring and Diagnosis of Failures in Squirrel-Cage Induction Motors Due to Cracked or Broken Bars". In: SDEMPED 2011 - 8th IEEE Symposium on Diagnostics for Electrical Machines, Power Electronics and Drives. Bologna, Italia, 05/09/2011, p. 39-44, Piscataway (NJ):IEEE, ISBN: 978-1-4244-9302-9, doi: 10.1109/DEMPED.2011.6063599
[27] Di Tommaso A O, Genduso F, Miceli R, Ricco Galluzzo G. "Experimental Validation of a General Model for Three Phase Inverters Operating in Healthy and Faulty Modes". In: International Symposium on Power Electronics, Electrical Drives, Automation and Motion SPEEDAM 2012. Sorrento (Italy), 20-22/06/2012, p. 50-55, Piscataway (NJ):IEEE, $\quad$ ISBN: 978-1-4673-1301-8. 10.1109/SPEEDAM.2012.6264571.

[28] H. A. Toliyat, S. Nandi, S. Choi, and H. Meshgin-Kelk, Electric Machines, Modeling, condition monitoring and Fault diagnosis. CRC Press, 2012.

[29] A.H. Bonnett, C. Yung, "Increased Efficiency Versus Increased Reliability", IEEE Industry Applications Magazine, Vol. 14, Issue 1, Jan./Feb. 2008.

[30] A. Bellini, F. Filippetti, C. Tassoni, G. A. Capolino, "Advances in Diagnostic Techniques for Induction Machines", IEEE Transactions on Industrial Electronics, vol. 55, no. 12, pp. 4109-4126, Dec. 2008.

[31] J. Mroz, "Temperature field of a double squirrel-cage motor during startup," Electric Power Applications, IEE Proceedings -, vol. 152, no. 6, pp. $1531-1538$, nov. 2005.

[32] A. Stefani, A. Yazidi, C. Rossi, F. Filippetti, D. Casadei, G.A. Capolino, "Doubly fed induction machines diagnosis based on signature analysis of rotor modulating signals," IEEE Transactions on Industry Applications, vol. 44, no. 6, pp. 1711-1721 , Nov./Dec. 2008.

[33] Y. Gritli, L. Zarri, C. Rossi, F. Filippetti, G. Capolino, and D. Casadei, "Advanced diagnosis of electrical faults in wound rotor induction machines," IEEE Transactions on Industrial Electronics (Accepted for publication), p. 1, 2012.

[34] A. Bellini, F. Filippetti, G. Franceschini, and C. Tassoni, "Closed-loop control impact on the diagnosis of induction motors faults," IEEE Transactions on Industry Applications, vol. 36, no. 5, pp. 1318-1329, Sep./Oct. 2000.

[35] S. M. A. Cruz and A. J. M. Cardoso, "Diagnosis of rotor faults in closedloop induction motor drives," in Conf. Rec. IEEE IAS Annu. Meeting, Tampa, FL, 2006, pp. 2346-2353.

[36] S. M. A. Cruz and A. J. M. Cardoso, "Analysis and diagnosis of rotor faults in high-performance induction motor drives," in Proc. Int. Conf. Elect. Mach., Chania, Greece, 2006, pp. 1-6.

[37] R. S. Weiser, C. Kral, and F. Pirker, "The Vienna induction machine monitoring method; on the impact of the field oriented control structure on real operational behavior of a faulty machine," in Proc. 24th Annu. IEEE-IECON, Aug. 31-Sep. 4, 1998, vol. 3, pp. 1544-1549.

[38] A. Ceban, R. Pusca, and R. Romary, "Study of rotor faults in induction motors using external magnetic field analysis," IEEE Transactions on Industrial Electronics, vol. 59, no. 5, pp. 2082 -2093, may 2012.

[39] A. Yazidi, H. Henao, G. A. Capolino, M. Artioli, F. Filippetti, and D. Casadei, "Flux signature analysis: An alternative method for the fault diagnosis of induction machines," in Proc. IEEE PowerTech, St. Petersburg, Russia, Jun. 2005, Paper n 424, CD-ROM.

[40] R.F. Walliser, and C.F. Landy, "Assessment of interbar currents in double cage induction motors with broken bars," IEEE Transactions on Energy Conversion, vol. 9, no. 1, pp.159-164, March 1994.

[41] A.O. Di Tommaso, R. Miceli, G. Ricco Galluzzo, "Monitoring and Diagnosis of Failures in Squirrel-Cage Induction Motors Due to Cracked or Broken Bar", IEEE-SDEMPED'2011, pp. 39-44, (Bologna) 2011.

[42] C. Concari, G. Franceschini, and C. Tassoni, "Differential Diagnosis Based on Multivariable Monitoring to Assess Induction Machine Rotor Conditions", IEEE Transactions on Industrial Electronics, vol. 55, no. 12, Dec. 2008.

[43] Y. Gritli, A.O. Di Tommaso, F. Filippetti, R. Miceli, and C. Rossi "Advanced Monitoring of Rotor Broken Bar in Double Squirrel Cage Induction Machines Based on Wavelet analysis", International Symposium Ecological Vehicle Exhibition and Renewable EnergiesEVER'2012, Monaco (France), Mars 2012.

[44] J. J. Rangel-Magdaleno, R. J. Romero-Troncoso, R. A. Osornio-Rios, E. Cabal-Yepez, and L. M. Contreras-Medina, "Novel Methodology for Online Half-Broken-Bar Detection on Induction Motors", IEEE Trans. on Inst. and Meas., vol. 58, no. 5, May. 2009. 